\title{
Jdentificação e Relação entre Professor (LE) e Formador em um Projeto de Educação Continuada
}

\author{
IdENTIFICATION AND RELATIONSHIP BETWEEN TEACHER (EFL) AND \\ Educator within a Continuing Education Project
}

Valdeni da Silva REIS *

Resumo: Este trabalho investiga alguns efeitos de sentido mobilizados a partir da ação do formador sobre professores de inglês, que, juntos, desenvolvem uma pesquisa-ação em um projeto de formação continuada. Assim, procuro explorar como são estabelecidos os lugares e as posições dos envolvidos nessa relação. $\mathrm{Na}$ análise de enunciados de professores e formadores, aponto elementos que indiquem tanto a aceitação, quanto a recusa nessa relação, discutindo quais os efeitos desses elementos para a prática do professor. Concluo indicando o modo que a identificação atua na constituição e mobilização da relação entre formador e professores no projeto de PESQUISA-AÇÃO, apontando, portanto, o modo com que essa relação ganha corpo na (nova) prática do professor de inglês como LE.

Palavras-chave: Pesquisa-ação; Relação-identificação; Professorformador.

Abstract: This study aims at investigating some meaning effects generated by the action of educators toward English teachers, as they develop together an action-research project within a continuing education program. Therefore, I explore the way in which discursive places and positions are established among the participants of the

\footnotetext{
* Doutorado em Linguística Aplicada pela Universidade Federal de Minas Gerais (UFMG). Professora substituta da Faculdade de Letras-UFMG. Contato: valdeni.reis@gmail.com
} 
research. The analysis of the data gathered from educators and teachers points towards both the acceptance and the resistance within the relationship among the participants. It also indicates the effects of such relationship on the teaching practice. Finally, this paper discusses how the identification among the participants constitutes and transforms their relationship within an action research project as well as its results to the practice of the English teachers.

Key-words: Action-research; Relationship-identification; Teachereducator.

\section{Introduzindo as (in)certezas de se assumir professor}

A profissão de professor tem enfrentado um crescente massacre e depreciação social. Ao mesmo tempo, vemos a proliferação de instituições de ensino que visam essencialmente ao lucro, em detrimento de uma qualidade na formação desse profissional. Como resultado, temos, muitas vezes, licenciados com uma formação deficiente.

Em sua atuação profissional, o professor pode enfrentar um cotidiano igualmente massacrante: salas cheias, indisciplina, violência, ausência de limites e de respeito; sem falar do salário e de todas as limitações de trabalho vivenciadas nas escolas.

O professor pode, ainda, enfrentar a sensação de um buraco entre a teoria "vista" na faculdade, e a complexidade da prática, vivenciada nos limites de sua sala de aula. Falando especificamente do professor de Língua Estrangeira (LE), apesar de parecer paradoxal, esse professor, muitas vezes, vive ainda o dilema de ensinar uma língua que ele próprio não domina, apresentando limitações linguísticas não sanadas em seu curso de Letras.

Concordo com Leffa (2001) que seja uma tarefa complexa para as instituições formar professores de LE competentes em termos linguísticos, comprometidos com a educação e com um fazer crítico. $\mathrm{O}$ autor também defende que tal tarefa se revela muito distante de ser alcançada completamente via curso de graduação, porque nessa formação são envolvidos tanto aspectos linguísticos quanto aspectos políticos. Para Leffa (2001, p. 333), 
a formação de um professor de línguas estrangeiras envolve o domínio de diferentes áreas de conhecimento, incluindo o domínio da língua que ensina, e o domínio da ação pedagógica necessária para fazer a aprendizagem da língua acontecer na sala de aula. A formação de um profissional competente nessas duas áreas de conhecimento, língua e metodologia, na medida em que envolve a definição do perfil desejado pela sociedade, é mais uma questão política do que acadêmica.

Não raras vezes, o professor enfrenta uma solidão em sua prática, enfatizada ou delimitada pela ausência de oportunidades para compreender e trabalhar os (in)sucessos e (in)certezas acerca da língua e da metodologia daquilo que ele ensina.

Diante desse quadro, ao professor cabem, pelo menos, duas saídas. A primeira, que pode parecer a mais fácil, é se revestir de todas essas dificuldades e se esconder em um discurso improdutivo e paralisante da culpabilização: não é possível sair dessa condição, sendo a culpa da escola, da formação, dos alunos, do pouco salário, etc.. Já a segunda, diz respeito à responsabilização, que, segundo Mrech (2005, p. 156), refere-se às nossas ações e decisões, sendo, portanto, “aquilo que fazemos, como fazemos, de que jeito fazemos, com quem fazemos, etc.”. Assim, entendo o conceito responsabilização como ato de se assumir, ou assumir sua condição, procurando compreender sua ação, sucessos e frustrações a despeito de todas as adversidades que "conspiram" contra esse fazer. Desse modo, a partir da responsabilização, o professor, a despeito de todas as dificuldades existentes, se torna responsável por aquilo que se dispõe a fazer em sua prática pedagógica.

Nessa posição de responsabilização, o sujeito-professor questiona sua prática, buscando compreender aquilo que não dá certo, sua solidão, suas angústias. Muitas vezes, é esse o principal sentimento que leva um professor a um projeto de educação continuada. Segundo Santiago [s.d.],

na verdade, há hoje um entendimento de que a formação se prolonga por toda a carreira. É requisito do processo de profissionalização, e, como tal, é uma estratégia de 
desenvolvimento profissional que se estende por toda a carreira como inserção de renovação profissional enquanto responsabilidade individual e coletiva. Essa é a formação continuada.

Educação ou formação continuada consiste em uma série de iniciativas teórico-metodológicas de formação oferecidas ao professor já em serviço.

Na Universidade Federal de Minas Gerais, desde o ano de 2002, há um Projeto de Educação Continuada de Línguas Estrangeiras (EDUCONLE), coordenado pela professora doutora Deise Prina Dutra. O EDUCONLE recebe professores de inglês da rede pública, para que estes tenham módulos teóricos, práticos e linguísticos.

No ano da coleta para a pesquisa aqui apresentada, havia o módulo da pesquisa-ação, meio pelo qual o professor era incentivado a investigar e (re)descobrir sua prática. Em poucas palavras, a pesquisaação pode ser compreendida como uma busca pela compreensão mais elaborada de perguntas relacionadas à prática do professor e/ou à solução de problemas previamente identificados em seu fazer pedagógico. A pesquisa-ação é, assim, conduzida por professores que desejam fazer algo para aprimorar sua prática. Nunan (1992) define pesquisa-ação, como um estudo de caso escolar, feito por professores que usam o status de participantes como base para desenvolver habilidades de observação e análise da prática docente.

A pesquisa-ação dentro do projeto EDUCONLE é de caráter colaborativo (SAGOR, 1993), uma vez que um grupo de professores de LE que compartilham interesses comuns trabalham juntos em uma dada investigação. Esse grupo de professores recebe a colaboração de um orientador ${ }^{1}$ que irá acompanhar todos os passos e desenvolvimento da pesquisa realizada na sala de aula desses professores. É na relação entre orientador e professores que residem as questões motivadoras da presente pesquisa.

${ }^{1}$ Essa orientação geralmente é assumida por professores da própria UFMG; por alunos do mestrado ou do doutorado da instituição ou por colaboradores oriundos de outras instituições de ensino. Utilizarei os termos orientador e formador sem distinção e intercaladamente. 
Importa-me discutir alguns possíveis efeitos de sentidos mobilizados a partir da ação do orientador-formador sobre professores de inglês como LE desenvolvendo juntos uma pesquisa-ação. De modo mais específico, a presente investigação se interessa pelo modo como a relação entre orientador e professor é constituída e mobilizada, ganhando corpo ou não na (nova) prática do professor de LE.

\section{RelAÇÃO e identificAÇÃO: o laço emocional}

A própria natureza humana pré-determina que o homem não seja outra coisa senão um ser relacional. Isso significa que, por toda sua história, desde seu nascimento, até sua morte, o homem, a revelia de sua própria vontade, é um ser que precisa se relacionar com outro: quando bebê sem o outro, não há sobrevivência; quando velho, a necessidade de ir e vir fica limitada ou até impossibilitada sem a presença do outro; quando morto, quem pode enterrar o ser humano senão o outro que ainda vive?

Fica, desse modo, simples compreendermos uma das definições da palavra relação no Grande dicionário Larousse cultural da língua portuguesa (LAROUSSE, 1999), no qual a palavra aparece como "elo de ligação, vínculo de dependência, de interação". Mais que uma dependência ou necessidade, relação tem a ver com experiência vivida e/ou partilhada com o outro. Relação significa estar em contato com outro, mas, ao mesmo tempo, estar em contato com a marca que esse outro deixa no próprio sujeito, como o ato de tatuar. Desse modo, relação tem a ver com o outro à sua volta, mas também (e principalmente) com o Outro (o inconsciente) que singulariza cada sujeito.

Nesses termos, considero relação como uma AÇÃO; como um movimento frente à experiência decorrente do enfrentamento com o outro. $\mathrm{Na}$ pesquisa desenvolvida por professores e o orientador, muitas são as ações delimitadas a partir da relação entre eles.

É somente na relação que o sujeito desenvolve não sua identidade - uma vez que não falo de algo uno, estável, acabado - mas sim, da identificação aqui assumida "como um processo em movimento, em que o sujeito se constitui pela multiplicidade de discursos, pela heterogeneidade e pelo descentramento de si" (ECKERT-HOFF, 2003, p. 288). No Dicionário de Psicanálise de Roudinesco e Plon (1998, p. 363 
- grifos dos autores) o termo identificação é resumido da seguinte forma:

termo empregado em psicanálise para designar o processo central pelo qual o sujeito se constitui e se transforma, assimilando ou se apropriando, em momentos-chave de sua evolução, dos aspectos, atributos ou traços dos seres humanos que o cercam.

Digo, portanto, que a relação é a condição primeira para que haja a identificação. Esta, por sua vez, faz com que o sujeito, além de se constituir, também se reinvente na dinâmica do contato com o outro. O conceito de identificação aparece ao longo da obra de Freud e particularmente em Psicologia de grupo e a análise do ego (1921). O autor inicia o capítulo intitulado Identificação definindo que esta "é conhecida pela psicanálise como a mais remota expressão de um laço emocional com outra pessoa". Esse laço, ainda nos termos do autor, é ambivalente, uma vez que pode se tornar "expressão de ternura com tanta facilidade quanto um desejo do afastamento de alguém".

Para o funcionamento e sucesso das investidas do grupo de pesquisa-ação assumo que a identificação é um elemento chave, uma vez que é ela quem estabelecerá se haverá ou não o laço responsável por fazer com que o grupo se mobilize, trabalhe. É importante, compreender aqui o lugar do orientador na constituição desse laço, dada a projeção que lhe é dirigida (pelo professor) desde o primeiro encontro.

Quando chega a um curso de educação continuada, o professor, de um modo geral, anseia por respostas às suas questões e solução para suas frustrações. Muitas vezes, essa expectativa é direcionada ao formador, tomado pelo professor como sendo seu ideal (FREUD, 1921). Caberá ao formador, portanto, trabalhar no sentido de trilhar um caminho que leve esse professor rumo a uma responsabilização por meio da qual ele investigará suas próprias questões. $O$ formador deverá orientar, mas, ao mesmo tempo, permitir e alimentar que a diferença de cada um se faça presente no grupo. Em última instância, cabe ao formador mobilizar o(s) sujeito(s) dessa relação, a ponto de fazer com que ele se separe da sua imagem (de formador) ideal e se responsabilize pelo trabalho em desenvolvimento. 
Freud (1921) defende que deve haver um laço mútuo entre os membros de um grupo, da ordem da identificação parcial, sendo esta baseada numa importante qualidade emocional comum e possível de se desenvolver a partir do laço com o líder. Segundo o autor, é essa qualidade que garante o início de um novo laço, sendo este o elemento que favorecerá a criação, levando os sujeitos dessa identificação para uma dimensão que amplia e recria o impulso inicial para além da imagem idealizada do outro; do querer ser como o outro.

A noção de identificação aparece na obra de Lacan a partir do registro imaginário pela noção do estádio do espelho ${ }^{2}$ (1998). Segundo tal noção, o ser humano ainda criança, ao ser confrontado com o espelho, assume uma imagem virtual de si como o seu “eu". É desse modo, que se (re)conhece ao (re)conhecer o outro, por meio dessa imagem de si, a qual se aliena. $\mathrm{O}$ adulto desempenha, portanto, um papel decisivo nessa constituição uma vez que é ele quem aponta a imagem no espelho como sendo a própria criança ("ali você"). É desse modo que é também pelo olhar do outro que o eu se constitui e constitui a forma de (se) ver (n)o mundo. A esse processo, Lacan (1998) nomeia de identificação. Entendemos, assim, que a constituição do "eu" ideal se dá a partir do momento em que o indivíduo, ainda criança, assume essa primeira identificação, a partir da qual, ao longo de sua vida, as outras identificações são constituídas ${ }^{3}$.

A relação entre formador e professor em formação continuada carrega muitos efeitos de sentido que delimitarão o sucesso ou insucesso de toda a pesquisa a ser desenvolvida pelo grupo, favorecendo ou impedindo que uma nova prática seja constituída. É desse modo que

${ }^{2}$ Segundo o dicionário de psicanálise de Roudinesco e Plon (1998, p. 194), essa expressão foi cunhada por Lacan em 1936, designando um momento psíquico e ontológico da evolução humana, localizado nos primeiros meses de vida (entre 6 a 18). Nesse período, a criança antecipa o domínio sobre sua unidade corporal por meio de uma identificação com a imagem do semelhante e da percepção de sua própria imagem num espelho. Os autores ainda explicitam que aqui, no Brasil, também encontramos essa expressão como "estágio do espelho" ou ainda "fase do espelho".

3 Ao longo de sua obra, Lacan reelabora a noção de identificação apresentada por Freud. No entanto, dada a limitação da presente proposta, não me aterei a esse seu trabalho. 
entendo o termo pesquisa-AÇÃO, como um movimento, um fazer, uma investida, que está no cerne tanto da relação quanto da possível identificação que delineará ou não o laço no grupo e o trabalho daí oriundo.

A seguir, apresentarei, brevemente, o modo de constituição do corpus aqui analisado, partindo, finalmente, para sua análise.

\section{Contexto, participantes e corpus analisado}

Este artigo investiga a relação entre professores de inglês da rede pública de ensino de Minas Gerais, e seus respectivos formadores durante o desenvolvimento de uma pesquisa-ação. Participam da pesquisa, portanto, três formadores e nove professores.

O corpus é formado por relatos orais (entrevistas) e escritos. Três formadores/orientadores responderam a um questionário (anexo 1) sobre sua orientação no projeto. Convidamos doze professores para participarem da pesquisa, sendo que nove deles responderam a outro questionário (anexo 2), enquanto três concederam uma entrevista semiestruturada a partir das perguntas apresentadas no questionário. A razão para termos questionário e entrevistas se deu apenas a partir da disponibilidade do participante.

Todos os nomes dos informantes são fictícios e também optei por não deixar registrado o ano da constituição do corpus para preservar a identidade dos participantes.

\section{Metodologia: constituição do corpus e marcas discursivas}

A presente análise seguirá o dispositivo de escuta discursiva (ORLANDI, 1999), por meio da qual são evidenciados os gestos de interpretação que se ligam aos processos de identificação constituídos nas relações entre os sujeitos, assim como nas filiações de sentidos nos quais os dizeres são formulados. Procuramos, por meio dessa escuta, descrever e interpretar a relação do sujeito, com o outro e com sua história, bem como os desdobramentos dessa relação nos grupos de pesquisa-ação.

O corpus será analisado com base nas ressonâncias discursivas (SERRANI-INFANTE, 2001), que define que há ressonância quando certas marcas linguístico-discursivas se repetem, tendendo a construir 
um significado predominante: as representações. Logo, a análise será pautada no conteúdo dos enunciados e nos modos de enunciar que os constituem. Em outras palavras, investigo o modo como os efeitos de sentido são produzidos, mobilizados e como ressoam para a constituição das relações movimentadas em um grupo de pesquisaação. Assim, interesso-me por aquilo que é dito e/ou intencionado dizer; pela contradição e conflitos e os já ditos (interdiscurso) que estão entrelaçados na materialidade daquilo que é dito, evidenciado no fio do discurso (intradiscurso).

Assim, o conjunto de categorias das ressonâncias discursivas quatro categorias e três subcategorias $-{ }^{4}$, é o seguinte:

1. repetição de itens lexicais de uma mesma família de palavras;

2. repetição de itens de diferentes raízes lexicais, apresentados no discurso como semanticamente equivalentes;

3. repetição de construções que funcionam parafrasticamente;

4. modos de enunciar presentes no discurso:

4.1. modo determinado e modo indeterminado de enunciar;

4.2. modo de definir por negações ou afirmações modalizadas ou categóricas;

4.3. modo de acréscimos contingentes por meio de incisas e de glosas.

Parto do princípio de que formador e professor falam de diferentes lugares e posições enunciativas. O lugar social constitui o que o sujeito diz e a partir do qual ele fala, enquanto a posição se relaciona à tomada da palavra discursiva (ORLANDI, 1999). Assim, lançando mão da palavra dita por sujeitos que ocupam lugares distintos - professor ou formador - aponto, abaixo, o modo como a relação entre formador e professores é constituída e mobilizada.

${ }^{4}$ Serrani-Infante (2001, p. 40) propõe apenas três categorias das repetições, a saber: a) itens lexicais de uma mesma família de palavras ou itens de diferentes raízes lexicais apresentados no discurso como semanticamente equivalentes; b) construções que funcionam parafrasticamente; c) modos de enunciar presentes no discurso (tais como o modo determinado e o modo indeterminado de enunciar; o modo de definir por negações, ou por afirmações modalizadas ou categóricas, modo de acréscimos contingentes através das incisas, glosas etc.). Porém, a partir de Reis (2006; 2007), utilizamos uma subcategorização, no intuito de facilitar a operacionalização de suas categorias. 


\section{Do amor à primeira vista à AÇÃo}

A partir do primeiro encontro e da descoberta de que poderá contar com a contribuição de um pesquisador mais experiente para $o$ desenvolvimento de seus trabalhos, há a possibilidade preeminente de uma identificação partindo dos professores. Nos termos de Mannoni (1994, p. 196), "uma identificação é uma captura. Aquele que se identifica talvez creia que está capturando o outro, mas é ele quem é capturado". Nessa captura o sujeito é poderosamente arrebatado, como um amor à primeira vista. Vejamos os excertos abaixo:

minha orientadora fez uma apresentação na primeira aula. Meus olhos brilhavam e eu vibrava porque me senti envolvida, fiqueipensando: ah, ela poderia ficar com o men grupo... desejei e consegui trabalhar com ela. [...] (Professora Sandra. Relato Escrito)

na verdade / na primeira reunião que nós tivemos aqui / vocês / orientadores / nós não sabíamos que seriam os orientadores / [...] e eu comecei assim / meu Deus / abençoe / abençoe que saia a Eduarda / a Lúcia / e assim / por sorte / eu saí com a Lúcia / en fiquei muito satisfeita / [...] (Professora Carla. Entrevista)

O laço é um envolvimento, como aponta Sandra em seu relato: "me senti envolvida". A captura passa, assim, pelo corpo, ("me senti" / "meus olhos brilhavam") e, na ilusão de completude, de ter aquilo que lhe falta, ou querer capturar o outro - sem se dar conta de que está sendo capturada - Sandra deseja o outro ("ah, ela poderia ficar com o meu grupo... desejei e consegui trabalhar com ela"). E o amor se dá à primeira vista ("minha orientadora fez uma apresentação na primeira aula" / "na primeira reunião e eu comecei assim / meu Deus / abençoe / abençoe que saia a Eduarda / a Lúcia”). Há, em termos freudianos, a expressão evidente de um laço emocional (e inicial) com outra pessoa, no caso com a orientadora.

Dada essa captura inicial, é somente na relação que o laço ganha forma ou não. Essa experiência se dá por ações e se transmite fazendo com que o outro se movimente e trabalhe, como apontado na continuidade da fala da Sandra e também da Carla: 
[...] Eu sentia o seu entusiasmo e a vontade que o grupo funcionasse unido e integrado. A todo instante eu me senti segura e com vontade de fazer, aprender e acertar. (Professora Sandra, Relato Escrito)

[...] e eu não estive enganada em momento algum / porque o retorno que a Lúcia nos deu foi muito positivo / ela foi muito sincera / ela foi muito árdua quando precisou / ela conseguiu chamar a atenção do grupo / e ao mesmo tempo ela foi muito mãezona / ela soube dosar / (Professora Carla. Entrevista)

Os excertos acima apontam o encaixe e a projeção delineada a partir do primeiro encontro e da ação desenvolvida pelo orientador no decorrer do processo, correspondendo com as expectativas advindas da primeira captura. No entanto, sabemos que o amor à primeira vista pode não perpetuar o encantamento da captura inicial. Às vezes, na ausência de envolvimento aparente, algo se esvai. Nesse sentido, vejamos os excertos abaixo:

No primeiro contato, sentimos que teríamos dificuldades em trabalhar com ela, pois pensamos que cobraria muito de nós, etc. Mas foi o contrário! (Professora Mariana. Relato Escrito)

[...] teve / assim / um afastamento / um pouco / dela com o grupo / né / mas com relação a / a/ / à competência / não tenho que dizer nada / acho ela MUITO competente / MUITO inteligente / / né / e/ mas faltou assim / uma / um / ABRACO maior / assim / no final / né / e a gente perdeu muito / [...] faltou integração MESMO / / e a gente sentiu assim / / e / em algumas horas / a gente sentiu meio vazio / né / o grupo / tentava comunicar / e às vezes / não recebia às vezes respostas / (Professor Joaquim. Entrevista)

A partir do primeiro encontro e da imagem inteligente, competente, mas também exigente transmitida pelo orientador, Mariana afirma que pensou que ela e seu grupo teriam dificuldades devido à possível cobrança acentuada de sua orientadora: "teríamos dificuldades em trabalhar com ela, pois pensamos que cobraria muito de nós", no entanto, 
foi exatamente o contrário. Em outras palavras, tiveram sim a dificuldade, não resultante de uma cobrança, mas justamente pela ausência.

Parece que o lugar de orientador desse grupo se revelou como um lugar vazio: "a gente sentiu assim / / e / em algumas horas / a gente sentiu meio vazio". Faltou o envolvimento metaforizado pela formulação "faltou abraço", e isso nos dá uma primeira certeza na/ da relação entre formador e professor: no processo identificatório é necessário o envolvimento (abraço) para que o laço seja mantido e traduzido posteriormente em deslocamentos ${ }^{5}$ subjetivos, logo em trabalho, em criação. Dessa forma, competência e inteligência são características colocadas em segundo plano, marcado na fala do enunciador, a partir do uso da incisa adversativa "mas", que muda o rumo do discurso, revelando outro lado: "acho ela MUITO competente / MUITO inteligente / / né / e/ mas faltou assim / uma / um / ABRAÇO [...]”.

Em um grupo de pesquisa-ação formado por professores e um orientador, o lugar desse último não é ocupado por qualquer outro membro do grupo, uma vez que o requisito básico para tal ocupação é justamente a experiência no que se refere à pesquisa; é o saber-fazer, numa relação de poder (FOUCAULT, 2005) legitimado e até institucionalizado por esse saber. Para Foucault (2005), existem técnicas disciplinares nas instituições que dizem respeito à forma como o eu é construído por outras pessoas, por discursos oficiais e, sobretudo, pelo poder-saber. Nesses termos,

uma relação de fiscalização, definida e regulada, está inserida na essência da prática do ensino: não como uma peça trazida ou adjacente, mas como um mecanismo que lhe é inerente e multiplica sua eficiência. (FOUCAULT, 2005, p.148)

5 A partir de Neves (2008), o termo deslocamento é entendido "como algum movimento que retira o sujeito de uma determinada posição enunciativa para outra, não necessariamente significando que houve mudanças, mas sim algum desvio, alguma desarticulação, ou desprendimento de certas representações, para até mesmo voltar a elas de outro modo ou para dar lugar a outras". 
Vejamos os excertos que se seguem:

O professor da pesquisa-ação representou um ponto de referência na construção da mesma. Sem a ajuda deste profissional, com suas ponderações acadêmicas e seu conbecimento amplo no campo de pesquisas, talvez a pesquisa-ação não teria êxito. (Professora Valéria. Relato Escrito)

// a importância dele é dá esse norte / né/ porque se não tiver alguém / pra falar / ó / você tem que fazer um texto com essa / dessa forma / você não pode / é:: / ramificar nisso / você tem / é isso e aquilo / então acho assim / é importante / as vezes uma pergunta um toquezinho que o orientador dá / já clareia // as vezes a gente tem tanta idéia na cabeça quando a gente começa a fazer a pesquisa / aí fica aquele brainstorm / aquela chuva de palavras que a gente não sabe como começar / quando chega alguém / ó Marcelo / faz isso aqui / assim / é assim mostra os passos / clareia muita coisa / né / ai facilita muito / ai sai o texto / as coisas (XXX) (Professor Joaquim. Entrevista.)

// / ela tem contribuido bastante / entendeu / é / assim / ajudado / é / é / procurando / tudo // é / pra gente / fazer o trabalho melhor possivel / ela sempre apresenta dados / como / como / é // desenvolver a pesquisa / [...] por causa da experiência que ela já tem / [...] / (Professora Carmen. Entrevista)

Diante da reincidência de determinadas marcas linguísticas discursivas ao longo de todo corpus, é possível afirmar que o orientador é colocado em um lugar como "ponto de referência" e "norte" e é a partir desse lugar que ele precisa enunciar, como vemos, por exemplo, nos excertos acima: "O professor da pesquisa-ação representou um ponto de referência na construção da mesma” / "a importância dele é dá esse norte”. Ao orientador é atribuído esse lugar, dado seu saber-fazer, sua experiência e conhecimento, elementos reincidentes no corpus como características necessárias. Essa experiência - saber-fazer - garante ao dizer do orientador um status de verdade absoluta: "sem a ajuda deste profissional, com suas ponderações acadêmicas e seu conhecimento amplo [...] não teria êxito". 
Parece essencial que o orientador tenha uma dimensão do peso de seu fazer para as atividades desenvolvidas pelo grupo. Vejamos o que os orientadores falam sobre seu lugar nessa pesquisa:

Bem, meu trabalho no grupo é orientar as participantes (são cinco professoras de inglês da rede estadual de Minas). Essa orientação consiste em mostrar como conduðiir a pesquisa-ação em sala de aula, tentando relacionar a teoria lida durante o curso às realidades educacionais nas quais estão inseridas essas professoras. [...] Acho que minha função é bastante relevante, pois é uma maneira de se tentar manter a organização e o andamento do trabalho e a coesão do grupo, além de se experimentar, na prática, o trabalho em equipe, a troca de conhecimentos e experiências, que, dada a natureza das trocas, acaba por tornar irrelevante relações de bierarquia que poderiam se estabelecer nesse tipo de contexto. (Formadora Lúcia. Relato Escrito.)

A relação requer grande empenho de todas as partes, primeiramente do formador/orientador, eu entendo. Pois, sempre sinto que os grupos com os quais trabalho precisam de um tempo de assimilação do que realmente eu "significo" para eles. Não sou "a dona da verdade", mas muitas vezes o formador é encarado assim, e aí, há espaço para resistência. (Formadora Eduarda. Relato Escrito)

Via reincidência de dizeres dos formadores, entendo que este se vê como aquele responsável por conduzir, oferecer elementos que possibilitem a união entre teoria e prática; a organização e funcionamento das investidas na pesquisa. Há também a constante reorganização do lugar do orientador frente à demanda de "dono da verdade": "Não sou 'a dona da verdade, mas muitas vezes o formador é encarado assim, e aí, há espaço para resistência”. O modo como o orientador se posiciona ou não como "dono da verdade" pode gerar a aceitação ou resistência por parte dos professores.

Lúcia no excerto acima, afirma que "dada a natureza das trocas, acaba por tornar irrelevante relações de hierarquia que poderiam se estabelecer nesse tipo de contexto". Essa afirmação não encontra, contudo, um consenso absoluto no corpus formado, como apontado no excerto abaixo: 
Acho que não há muita rejeição, já que nada é imposto. Há também a questão do poder: obviamente sou o membro que possui a mais alta bierarquia dentro do grupo e isso é inevitável. Toda e qualquer relação social envolve uma relação de poder, como apontou Foucault. [...] Conseguir alcançar algum equilíbrio nesse jogo é o objetivo do trabalho colaborativo, embora esteja claro que sempre haverá hierarquia e que os conflitos são inevitáveis. (Formadora Regina. Relato Escrito)

Concordo que, juntamente com o título de "orientador", vai também acoplado o efeito de sentido ligado "à mais alta hierarquia dentro do grupo" e todas as demandas oriundas dessa posição. Como vimos, caberá ao orientador e não a outra pessoa o papel de orientar, guiar, indicar leituras e até delegar funções. Vejamos abaixo:

/ ela conseguia / é / delegar as tarefas / [...] e com isso nós conseguimos organizar o nosso trabalho / [...] então ela foi a pessoa que assim / cumpriu / muito bem / o papel dela / que foi o de orientar / de organizar / e ela fez / (Professora Denise. Entrevista)

Como aponta Regina, a hierarquia existe dada a relação de poder oriunda do lugar ocupado pelo formador e seu consequente saberfazer. No entanto, é importante que tal hierarquia não paralise ou comprometa as (rel)ações. Pelo contrário, é necessário que a hierarquia seja também ressignificada nessa relação. Freud (1921), afirma que,

Concordando com Freud, o formador, um líder de grupo em potencial, será o laço ponto de referencia para todos os membros do grupo; cabe ao formador delinear o tipo de laço que será estabelecido nas atividades em grupo e isso é de qualidade emocional, daquilo que ele acredita e entende como papel de orientador. Trata-se, desse modo, de uma identificação.

Observemos:

eu sentia o seu entusiasmo e a vontade que o grupo funcionasse unido e integrado. A todo instante eu me senti segura e com vontade de fazer, aprender e acertar. [...] Os e-mails constantes e uma "puxando a outra", nos envolvemos na pesquisa. Todas tinham o mesmo objetivo aprender 
e acertar, sem medo de errar. O processo foi constante integração, apoio, carinho e respeito. (Professora Sandra, Relato Escrito)

A identificação está no corpo; passa pelo corpo e é daí que surge a possibilidade de um novo laço a começar por aquele que foi capturado, levando o sujeito ao trabalho criativo, capaz de fazer com que o sujeito ressignifique seu fazer pedagógico.

Vejamos, por fim, como a ação do formador, pode tocar o professor, fazendo com que este invista na transformação de sua prática:

Minha orientadora fez despertar em mim a minha reflexão. Muitas vezes eu realizava alguma coisa e não refletia sobre 0 resultado e 0 processo, o escrever, o analisar falas, atos e até o silêncio me fez rever minhas atitudes e prática pedagógica. Durante todo o projeto ela me despertou a um caminhar reflexivo e constante. Este despertar, uma provocação para que minha reflexão não fosse interrompida, me ajudou $a$ não abandonar meus objetivos. Em cada encontro, cada e-mail fui impulsionada em querer mudar e acertar. Investigar minhas ações e a partir delas refletir e melhorar minha prática pedagógica. (Professora Sandra. Relato Escrito)

Ao propor uma investigação acerca do laço que se estabelece entre o formador e professor, interessei-me, concomitantemente, em investigar o tipo de produto oriundo dessa relação. Dado os relatos de formadores e, principalmente, dos professores, pontuo que em alguns grupos o amor à primeira vista foi alimentado, mantendo $\mathrm{O}$ encanto do primeiro encontro. A relação serviu para promover um despertar.

O orientador se revela com a função de "tirar do sono", de acordar, de mobilizar uma prática e/ou uma (falta de) ação: "minha orientadora fez despertar em mim a minha reflexão"; "durante todo o projeto ela me despertou a um caminhar reflexivo e constante. Este despertar, uma provocação para que minha reflexão não fosse interrompida, me ajudou a não abandonar meus objetivos".

Defendo, desse modo, que o orientador poderá impulsionar o professor a investigar as incertezas de sua prática tão massacrada nos dias atuais, reformulando suas limitações quer sejam da ordem linguística, quer sejam da ordem teórico-metodológica. 


\section{Um porto seguro, mas nunca um esconderijo}

O caminho não foi fácil...

Lembrando os tropeços dessa viagem fico imaginando o que seria fácil num final tão grandioso. [...].

Gosto muito do mar, acho que a literatura portuguesa ficou muito registrada em mim. Navegar é preciso... Esta nossa viagem, à pesquisa, foi impar em todo processo. Você, nossa comandante MARAVILHOSA, SABLA, EXPERIENTE, CUMPLICE, fer. com que nossa viagem seguisse em frente com segurança.

Não gosto muito da metáfora "porto seguro" porque gosto muito de barcos, e eles não foram feitos para ficar nos portos. Você nos provocou tanto nessa viagem que não é possivel parar. (Sandra em mensagem eletrônica para sua orientadora)

Ao longo dessa escrita, defendi que a relação entre formador e professor em formação continuada é o elemento fundamental para o sucesso (ou insucesso) da pesquisa-ação a ser desenvolvida pelo grupo. Nesse sentido, as ações assumidas pelo formador afetam as (re)ações dos professores. Como apontado, nessa relação a identificação deve ser discutida como uma captura que favorece ou impede que o professor (re)signifique sua prática.

Concluo retomando duas falas dispostas acima. A primeira é um excerto da fala da professora Maíra que intitula essa seção; já a segunda, é o excerto escrito por Sandra que abre nossa conclusão.

Ao intitular e abrir essa última seção com os dizeres de Maíra e Sandra, dou voz ao eco de meu próprio fazer, não resistindo ao anonimato muitas vezes exigido para a pesquisa acadêmica. Concomitantemente, dou voz ao que é singular das/nas relações para que a mudança seja possível.

A ação do orientador pode produzir (embora não garantir) efeitos de sentido que mobilizarão a prática do professor, impulsionando-o a ir além de uma culpabilização na medida em que se assume em um fazer transformador. Por fim, é ainda prudente afirmar que os efeitos de sentido dessa relação vão muito além daquilo que, como orientadores-formadores, podemos prever, antever, ver, ou, aqui, discutir, uma vez que "não é [mais] possível parar". 


\section{Anexo 1}

\section{Questionário Formador}

1. Que lugar você atribui ao trabalho que você desempenha/ desempenhou juntamente com seu grupo de pesquisa-ação? O que você faz? (qual é seu papel / fazer no grupo?)

2. Quais são os princípios que impulsionam e delimitam sua atuação nesse processo?

3. Fale um pouco sobre a relação que se desenvolve com os membros do grupo (com o grupo) que você orienta?

4. Como você enxerga os professores que fazem/fizeram parte de seu grupo?

5. Fale um pouco das certezas e /ou incertezas que se fazem / ou se fizeram presentes durante o processo de orientação.

6. Qual peso você acha que seu dizer tem/teve/terá sobre o fazer desses professores?

7. Fale sobre a rejeição e/ou aceitação de seu dizer e fazer para o grupo.

8. Você acha que seu fazer terá algum lugar na prática desses professores após EDUCONLE?

9. Gostaria de fazer algum comentário sobre algo que não foi citado por meio das perguntas propostas acima?

\section{Anexo 2}

\section{Questionário Professores}

1. Como você enxerga/enxergou o professor que te orienta em sua pesquisa-ação? (falar de sua (não) importância) (comente a AÇÃO desse orientador nesse processo de pesquisa)

2. A partir do primeiro encontro/contato, o que você passou a esperar dessa pessoa?

3. O que você recebeu/recebe de fato? (fale da relação entre você e o formador /bem como todo o grupo)

4. Comente a ação dessa pessoa na pesquisa-ação? (fale dessa pessoa) 5. Comente como e se a ação/o fazer dessa pessoa (orientador) vai para sua prática pedagógica? 
6. Fale da presença dessa pessoa e da pesquisa-ação em relação a tudo que você vivencia/vivenciou em todo o projeto de educação continuada. (comente)

7. Fale dessa pessoa (orientador e sua ação) em relação àquilo que ficará ou não após o projeto de educação continuada (EDUCONLE)?

\section{Referências}

ECKERT-HOFF, B. A denegação como possibilidade de "captura" do não-um no tecido do dizer. In: CORACINI, M.J.F. (Org.) Identidade e discurso. Campinas: Argos/Ed. Unicamp, 2003. p. 285-302.

FOUCAULT, M. Vigiar e punir: nascimento da prisão. 30. ed. Trad. Raquel Ramalhete. Petrópolis: Vozes, 2005.

FREUD, S. Psicologia de grupo e a análise do ego. In: Edição eletrônica brasileira das obras completas de Freud. Rio de Janeiro: Imago, 1921. v. 23. CD-Rom.

LAROUSSE. Grande dicionário Larousse cultural da língua portuguesa. São Paulo: Nova Cultural, 1999.

LACAN, J. Escritos. Rio de Janeiro: Jorge Zahar, 1998 [1964].

MANNONI, O. A desidentificação. In: ROITMAN, A. (Org.) As identificaçôes. Rio de Janeiro: Relume-Dumará, 1994. p.173-200.

MRECH, L.M. O impacto do terceiro ensino de Lacan: novas contribuições para algumas articulações possíveis entre psicanálise e educação. In: - (Org.). O impacto da psicanálise na Educação. São Paulo: Avercamp, 2005. p. 143-158.

NEVES, M.S. Identificações subjetivas no discurso sobre avaliação de aprendizagem após um curso de educação continuada. Horiz̧ontes, v. 26, n. 2, p. 21-29, jul./dez. 2008

NUNAN, D. Research methods in language teaching. Cambridge: Cambridge University Press, 1992. 
ORLANDI, E.P. Análise de discurso: princípios e procedimento. Campinas: Pontes, 1999.

REIS, V.S. Análise das representações em diários de alunos de Língua Estrangeira. In: MACHADO, L.; MENEZES, W.A. (Orgs.). Gêneros, comunição e sociedade. Belo Horizonte: Faculdade de Letras da UFMG, 2006. 1 CD-Rom.

- O diário de aprendizagem de língua estrangeira (Inglês) sob a perspectiva do processo discursivo. 2007. 143p. Dissertação (Mestrado em Estudos Linguísticos) - Universidade Federal de Minas Gerais, Belo Horizonte. 2007.

ROUDISNESCO, E.; PLON. M. Dicionário de Psicanálise. Trad. Vera Ribeiro; Lucy Magalhães. Rio de Janeiro: Jorge Zahar, 1998.

SAGOR, R. How to conduct collaborative action research. Alexandra: Virginia ASCD, 1993.

SANTIAGO, M. E. Formação continuada nas dimensões: natureza humana, direito profissional e parâmetro de profissionalização. [s.d.] Disponível em: <http://www.construirnoticias.com.br/asp/ materia.asp?id $=741>$. Acesso em: 20 nov. 2008.

SERRANI-INFANTE, S. M. Abordagem transdisciplinar da enunciação em segunda língua: a proposta AREDA. In: SIGNORINI, I.; CAVALCANTI, M.C. (Orgs.) Lingüistica aplicada e transdisciplinaridade. Campinas: Mercado de Letras, 1998. p. 143-167. 